NBER WORKING PAPER SERIES

\title{
DOES MENTORING INCREASE THE COLLABORATION NETWORKS OF FEMALE ECONOMISTS? AN EVALUATION OF THE CEMENT RANDOMIZED TRIAL
}

\author{
Donna K. Ginther \\ Rina Na \\ Working Paper 28727 \\ http://www.nber.org/papers/w28727
NATIONAL BUREAU OF ECONOMIC RESEARCH
1050 Massachusetts Avenue
Cambridge, MA 02138
April 2021

This research was funded by National Science Foundation Grant SES-1547054. We thank Carlos Zambrana and Patricia Oslund for assisting with Web of Science searches. We thank Shulamit Kahn, Janet Currie, and Karen Mumford for comments on the paper. We are grateful to the many women who volunteered their time to participate in the CeMENT mentoring experiment. A randomized controlled trials registry entry is available at AEARCTR-0000136. Any errors are our own responsibility. The views expressed herein are those of the authors and do not necessarily reflect the views of the National Bureau of Economic Research.

NBER working papers are circulated for discussion and comment purposes. They have not been peerreviewed or been subject to the review by the NBER Board of Directors that accompanies official NBER publications.

(C) 2021 by Donna K. Ginther and Rina Na. All rights reserved. Short sections of text, not to exceed two paragraphs, may be quoted without explicit permission provided that full credit, including $\odot$ notice, is given to the source. 
Does Mentoring Increase the Collaboration Networks of Female Economists? An Evaluation of the CeMENT Randomized Trial

Donna K. Ginther and Rina Na

NBER Working Paper No. 28727

April 2021

JEL No. A11,J16,J4

\begin{abstract}
$\underline{\text { ABSTRACT }}$
Previous research has shown that women in the treatment group of the CeMENT randomized controlled trial increased their publications and the likelihood that they were tenured in top 50 economics departments. This paper examines one potential mechanism, namely, that CeMENT expanded the collaboration networks of the participants. Our analysis finds that women who received the mentoring treatment had three additional pre-tenure coauthors, 1.6 more pre-tenure publications and 43 additional citations to those publications. After controlling for additional coauthors, the CeMENT program increased publications, and top-tier publications. These results suggest that the information conveyed at the workshop facilitated participants' career success.
\end{abstract}

\author{
Donna K. Ginther \\ Department of Economics \\ University of Kansas \\ 333 Snow Hall \\ 1460 Jayhawk Boulevard \\ Lawrence, KS 66045 \\ and NBER \\ dginther@ku.edu \\ Rina $\mathrm{Na}$ \\ PRA Health Science \\ 9755 Ridge Drive \\ Lenexa, KS 66219 \\ rina.na1988@gmail.com
}


Women in the economics field are less likely to get tenure (Ginther and Kahn 2004, Ginther and Kahn 2014, Ginther and Kahn forthcoming) when compared to their male colleagues. Research productivity is cited as one of the major reasons for the gender difference in economic careers in academia (Conley, Önder and Torgler 2016, Conley and Önder 2014). Studies have shown that collaborations among economists are positively related to the overall productivity of both men and women (McDowell, Singell and Stater 2006). In this study, we investigate the impact of the CeMENT mentoring randomized controlled trial on coauthorship networks. Our results show that the CeMENT workshop expanded coauthorship networks among treated women, but these additional coauthors do not fully explain the positive impact of the mentoring workshop.

\section{The Importance of Collaboration in Research Productivity}

Lower research productivity is often cited as a primary reason for women's disadvantage in academic careers. Conley, Önder and Torgler (2016) found that research productivity is positively related with the availability of academic jobs for both genders. Women's responsibility in childbearing and caregiving negatively affects their research productivity (Joecks, Pull and Backes-Gellner 2014, Krapf et al. 2014). At work, women devote more time in

teaching and other non-research obligations (Taylor, Fender, and Burke 2006, Harter, Becker and Watts 2011, Manchester and Barbezat 2013).

Coauthorship is increasingly important for research productivity in economics (Hamermesh 2012). Several researchers have examined coauthorship and its impact on academic research productivity (Laband and Tollison 2000, Hamermesh 2012). Although many researchers have shown a positive association between coauthorship and research productivity, establishing the causal effect of coauthorship is difficult due to the endogeneity of collaboration networks. 
Lee and Bozeman (2005) instrumented coauthorship using a scale for the location of coauthors. Common research interest between coauthors has also been used as instrument to handle the endogeneity of coauthorship networks (Ductor 2015).

A limited number of papers have studied women's collaboration networks. McDowell, Singell and Stater (2006) showed that female economists were less likely to coauthor than their male colleagues, indicating that lacking professional research networks might explain women's lower research productivity. However, women's smaller coauthorship networks may be a rational choice because Sarsons (2017) found that women were given less credit for coauthored work than men. In addition, Hengel (2017) and Card et al (2020) found that women economists may be held to a higher standard for publications than men.

Given the importance of collaboration to research productivity, we hypothesize that the CeMENT workshop provides a positive shock to collaboration networks. Since the CeMENT workshop is a randomized controlled trial, it may result in an exogenous change to professional networks for those who are treated, giving us an opportunity to examine the coauthorship networks of CeMENT participants compared to the control group.

\section{The CeMENT Randomized Controlled Trial}

With the support of the National Science Foundation (NSF) and the American Economic Association (AEA), the AEA's Committee on the Status of Women in the Economics Profession (CSWEP) established the CeMENT mentoring program to support junior female economists. ${ }^{1}$

\footnotetext{
${ }^{1}$ CSWEP runs two mentoring workshops. The CeMENT Workshop for Faculty in Doctoral Programs https://www.aeaweb.org/about-aea/committees/cswep/programs/CEMENT-mentoring-workshops\#doctoral was originally a randomized controlled trial and is the source of data for this paper. The workshop is held immediately following the ASSA meetings. The CeMENT Workshop for Faculty in Non-Doctoral programs https://www.aeaweb.org/about-aea/committees/cswep/programs/CEMENT-mentoring-workshops\#nondoctoral is held in conjunction with a regional economic association meeting. The Non-Doctoral workshop was not designed as
} 
The National Workshop (now the Workshop for Faculty in Doctoral Programs) focuses on junior female economists employed at institutions where research accomplishments weigh heavily in the promotion decision. It was originally designed as a randomized controlled trial and was held every other year from 2004 to 2014. The AEA funded the workshop every year starting in 2015. Previous studies have shown that the CeMENT program increased the number of publications, publications in top journals, and the number of federal grants for treated cohorts and increased the likelihood that women remained in academia as well as promotion to tenure in top-ranked economics departments (Blau et al. 2010; Ginther et al. 2020). However, neither evaluation has fully investigated the mechanism contributing to the improvement in publication outcomes.

The CeMENT Mentoring Workshop for Faculty in Doctoral Programs was designed to provide role models (senior female economists) and peers in one's research field. The workshop is held immediately after the ASSA meetings and lasts two days. Between 40 and 50 junior faculty attend and are divided into groups of 4 to 5 women in the same field. Two senior female economists in the same field are assigned to mentor each group. Prior to the conference, each woman circulates a research paper that will be read and discussed by the group. In between group sessions, plenary sessions made up of a panel of senior mentors focused on the topics of research and publishing, getting grants, networking strategies, teaching, the tenure process, and work-life balance. Thus, the CeMENT intervention focused on strategies for publishing research as well as providing comments on a specific paper. In addition, the networking strategy session focused on how to increase professional exposure.

a randomized controlled trial and does not emphasize the same professional development topics as the Doctoral Workshop. 
Approximately 80 people applied to each workshop. Applications were screened by completeness and research intensity of an applicant's current institution (those at teachingfocused universities were re-directed to the Non-Doctoral Workshop). Applicants were assigned to groups based on research field (e.g. Labor, Macroeconomics, Health, Development, etc.). Within each field, applicants were randomly assigned to treatment or control groups, and more applicants were treated than not (e.g. if there were eight applicants in a field, five were selected as treatments). All applicants were told that there were more applications than slots available in the workshop, and several women reapplied for the workshop.

\section{Data on Publications and Methods}

We collected the curricula vitae (CVs) and Web of Science publications of the applicants to the CeMENT workshop. Our Web of Science queries for publications were based on five years prior to the doctorate through the third quarter of 2018. We collected data on the first eight CeMENT cohorts from 2004-2016. We did not include the most recent cohorts because it will take time for potential new collaborations to result in additional publications. In total, there are 512 people in the data. ${ }^{2}$ We rank the quality of the doctoral department and first job using the world rankings of institutions in economics from Kalaitzidakis, Stengos, and Mamuneas (2003).

Our WOS publication data contain information on year of publication, journal, affiliations, coauthor names, and citations. We ranked journals based on quality. Top Tier journals are the American Economic Review, the Journal of Political Economy, the Quarterly Journal of Economics, Econometrica, and the Review of Economic Studies. Top Field journals are in our second category, and Other Refereed publications are all journals indexed in WOS that

\footnotetext{
${ }^{2}$ Our sample includes more cohorts of data compared to Ginther et al (2020) that restricted the sample to people who had sufficient time for promotion to tenure.
} 
are not categorized as Top Tier or Top Field. Since we are interested in the mechanisms associated with the CeMENT workshop we focus on pre-tenure publications as in Ginther et al. (2020). We identified 3,161 pre-tenure publications of which 136 were Top Tier, 1,023 were Top Field and 2,002 were Other Refereed.

We identified the number of unique coauthors by publication years and used that data to identify the number of coauthors prior to receiving the mentoring treatment and the number of additional coauthors after treatment but pre-tenure. In addition, we identified only 20 publications that resulted from the CeMENT workshop. Two women collaborated on multiple publications with women in their same cohort (8 publications); 10 women collaborated on one publication with another member of their cohort (5 publications); 3 women collaborated with a CeMENT mentor (3 publications); and 2 women collaborated on 2 publications each with a CeMENT mentor (4 publications).

Table 1 lists the cohort year and number of treatment and control groups. Appendix 1 provides more details about our data collection methods. As mentioned earlier, 83 out of the 512 women in our sample reapplied for the workshop and 60 of those women eventually received the mentoring treatment. We follow Ginther et al. (2020) in using an intent-to-treat framework where the initial assignment to the treatment or control group is used as an instrument for whether a person was eventually treated.

Table 2 compares the characteristics of the sample prior to the CeMENT workshop. There are few significant differences between the treatment and control groups. Between 86 and $90 \%$ of the applicants had an academic first job. Over half of the sample (53-56\%) obtained their PhD at Top 10 or 20 ranked institutions. Women in the treatment and control groups had on average 1.3 to 1.6 pretreatment coauthors. We found two significant differences in pre-CEMENT 
characteristics. First, the treated group received their doctorates on average one year earlier than the control group. Second, the control group includes more women whose first job was at an unranked (201+) academic institution. These differences are likely the result of changes in CeMENT policies after 2014 that gave women who previously applied to the workshop the opportunity to participate in subsequent workshops. In all estimates we control for years since $\mathrm{PhD}$, the initial CeMENT cohort, and pre-treatment coauthors in order to adjust for the CeMENT applicant's initial collaboration network. In addition, we split the sample by first job at a top 200 ranked institution (Ranked) and 201+ ranked as well as nonacademic institutions (Unranked).

\section{Results}

Table 3, Panel A reports our main results on the effect of the CeMENT treatment on pretenure publications, coauthors and total citations as of 2018 using the full sample. All models use initial treatment assignment as an instrument for the probability of ever receiving treatment. Women who participated in the CeMENT workshop published 1.6 more papers (representing a 26\% increase at the mean), 0.21 additional Top Tier papers (representing a 78\% increase), and 0.96 additional Other Refereed papers (representing a 16\% increase), all statistically significant at $\mathrm{p}<0.05$. As found in the previous literature, there is a significant relationship between the number of coauthors and publications. Each additional pretreatment coauthor contributed 0.79 in additional publications. However, the number of coauthors have no impact on Top Tier publications.

In addition, the CeMENT workshop significantly expanded a woman’s pre-tenure collaborations, adding 3 additional coauthors relative to the treatment group (a 51\% increase). However, these additional collaborations were not directly the result of collaborations formed at the CeMENT workshop. After adjusting for CeMENT papers, the treated group still had an 
average of 3 more coauthors than the control group. Finally, the treatment group had 43 more citations to pre-tenure publications than the control group (a $45 \%$ increase).

Panel B of Table 3 reports the same results for the subsample of women whose first job was at a top 200 ranked academic institution. We see similar results for total publications (1.3 more), but no significant difference from the control group for other publication measures. However, women whose first job was at a ranked institution who received the mentoring treatment have 3.4 additional coauthors (a 52\% increase over the mean). Citations are not significantly different between the treatment and control groups. Panel C repeats the analysis for women whose first job was at an unranked academic or a nonacademic institution. The women in the treatment group have more total publications than those at ranked institutions 1.6 compared to 1.3. Most of this increase is made up of Other Refereed publications. Women in the treatment group have 1.3 more Other Refereed publications than the control group, an increase of 33\% at the mean. Also, women in the treatment group have an additional 61 citations, representing an 84\% increase. However, treated women whose first job was at unranked or nonacademic institutions who received the mentoring treatment have one fewer coauthor (2.3 compared to 3.4) than women at ranked institutions. In fact, the average number of coauthors in the two groups differs by 1.7 .

The final panel of Table 3 re-estimates the models for the full sample including controls for coauthors added after the CeMENT workshop as well as pre-treatment coauthors. After controlling for all pre-tenure coauthors, women who received the mentoring treatment had an additional 0.57 publication (a 9\% increase). Although much of the publication effect for treated women is explained by controlling for coauthors, the mentoring treatment still has a marginally significant $(\mathrm{p}<0.10)$ effect. We also find that coauthors explain none of the highly significant 
effect of the mentoring treatment on Top Tier publications. Finally, we find that mentoring treatment contributes to 31 additional citations $(\mathrm{p}<0.07)$ after controlling for all pre-tenure collaborators, a 32\% increase.

In Appendix 2, Table A1, we limited the sample to those who were in the analysis sample in Ginther et al. (2020) and present the estimates in Table 3 for that sample. The results are very similar to those in Table 3, although the magnitude of the estimates is somewhat larger. In particular, the treated women add 3.5 more coauthors compared to the control group. In the bottom panel women in the treatment group have an additional .8 publication (an 11\% increase) after controlling for all pre-tenure coauthors.

\section{Conclusions}

Researchers have found that women publish fewer papers than men, have more difficulty publishing their work, and are given less credit for coauthored work. The CeMENT randomized controlled mentoring trial has shown that mentoring increases the number and quality of publications (Blau et al. 2010, Ginther et al. 2020). This paper examines whether the increase in publications is the result of expanded coauthoring networks.

We found that the mentoring treatment increases publications, Top Tier publications, Other Refereed publications, and total citations. In addition, the treatment increased the number of pretreatment coauthors by three relative to the control group. We were expecting that this increase in networks would be the result of new collaborations formed at the CeMENT workshop but found that was not the case. Networks also grew larger at ranked academic institutions relative to unranked institutions. 
Once we control for the number of pre-tenure coauthors, the estimated impact of the mentoring treatment on publications is significantly reduced, but not eliminated. Taken together, these results suggest that the CeMENT workshop provided information and advice that contributed to the expansion of collaboration networks and the career success of treated women. Although women at unranked academic and nonacademic institutions had smaller increases in their number of coauthors, the mentoring treatment increased their publications and citations as well. Thus, it remains a troubling puzzle that these women were less successful in achieving tenure than women at the top-ranked institutions (Ginther et al. 2020). Unfortunately, Ginther and Kahn (forthcoming) found evidence that women at less research-intensive universities were less likely to be promoted than men after controlling for publications and citations, suggesting that unobservable factors including bias may be playing a role. 


\section{References:}

Blau, Francine D., Janet M. Currie, Rachel T. A. Croson, and Donna K. Ginther. 2010. "Can Mentoring Help Female Assistant Professors? Interim Results from a Randomized Trial." American Economic Review 100 (2): 348-52.

Card, David Stefano DellaVigna, Patricia Funk, Nagore Iriberri. 2020. "Are Referees and Editors in Economics Gender Neutral?” The Quarterly Journal of Economics 135(1): 269327. https://doi.org/10.1093/qje/qjz035.

Conley, John P., Ali Sina Önder, and Benno Torgler. 2016. “Are All Economics Graduate Cohorts Created Equal? Gender, Job Openings, and Research Productivity.” Scientometrics 108(2): 937-958.

Conley, John P., and Ali Sina Önder. 2014. "The Research Productivity of New PhDs in Economics: The Surprisingly High Non-success of the Successful." Journal of Economic Perspectives 28 (3): 205-16.

Ductor, Lorenzo. 2015. “Does Co-Authorship Lead to Higher Academic Productivity?” Oxford Bulletin of Economics and Statistics 77(3): 385-407.

Ginther, Donna K., and Shulamit Kahn. 2004. "Women in Economics: Moving Up or Falling Off the Academic Career Ladder?” Journal of Economic Perspectives 18(3): 193-214.

Ginther, Donna K., and Shulamit Kahn. 2014. “Academic Women’s Careers in the Social Sciences: Progress, Pitfalls and Plateaus.” In The Economics of Economists: Institutional Setting, Individual Incentives, and Future Prospects, edited by Alessandro Lanteri and Jack Vromen, 285-315. Cambridge: Cambridge University Press.

Ginther, Donna K., Janet M. Currie, Francine D. Blau, and Rachel T. A. Croson. 2020. "Can Mentoring Help Female Assistant Professors in Economics? An Evaluation by Randomized Trial.” American Economic Review Papers and Proceedings 110: 205-209.

Ginther, Donna K., and Shulamit Kahn. (Forthcoming). "Women in Academic Economics: Have We Made Progress?” American Economic Review Papers and Proceedings.

Hamermesh, Daniel S. 2012. "Six Decades of Top Economics Publishing: Who and How?" Journal of Economic Literature 51(1): 162-172.

Harter, Cynthia L., Willian E. Becker, and Michael Watts. 2011. "Time Allocations and Reward Structures for US Academic Economists from 1995-2005: Evidence from Three National Surveys.” International Review of Economics Education 10(2): 6-27.

Hengel, Erin. 2017. "Publishing While Female. Are Women Held to Higher Standards? Evidence from Peer Review.” https://doi.org/10.17863/CAM.17548

Joecks, Jasmin, Kerstin Pull, and Uschi Backes-Gellner. 2014. "Childbearing and (Female) Research Productivity: A Personnel Economics Perspective on the Leaky Pipeline”. Journal of Business Econ 84, 517-530. https://doi.org/10.1007/s11573-013-0676-2 
Kalaitzidakis, Pantelis, Thanasis Stengos, and Theofanis P. Mamuneas. 2003. "Rankings of Academic Journals and Institutions in Economics." Journal of the European Economic Association, 1(6): 1346-1366.

Krapf, Matthias, Heinrich W. Ursprung, and Christian Zimmermann. 2017. "Parenthood and Productivity of Highly Skilled Labor: Evidence from the Groves of Academe.” Journal of Economic Behavior \& Organization 140: 147-175.

Laband, David N., and Robert D. Tollison. 2000. “Intellectual Collaboration.” Journal of Political Economy 108(3): 632-662.

Lee, Sooho, and Barry Bozeman. 2005. "The Impact of Research Collaboration on Scientific Productivity.” Social Studies of Science 35(5): 673-702.

Manchester, Colleen, and Debra Barbezat. 2013. “The Effect of Time Use in Explaining Male-Female Productivity Differences Among Economists”. Industrial Relations: A Journal of Economy and Society 52(1): 53-77.

McDowell, John M., Larry D. Singell, and Mark Stater. 2006. “Two to Tango? Gender Differences in the Decisions to Publish and Coauthor.” Economic Inquiry 44(1): 153168.

Sarsons, Heather. 2017. "Recognition for Group Work: Gender Differences in Academia.” American Economic Review Papers and Proceedings 107(5): 141-145.

Taylor, Susan Washburn, Blakely F. Fender, and Kimberly G. Burke. 2006. "Unraveling the Academic Productivity of Economists: The Opportunity Costs of Teaching and Service." Southern Economic Journal 72(4): 846-859. 
Table 1: CeMENT Cohort Data

\begin{tabular}{cccccc}
\hline Cohort & Year & Treatment & Control & Reapplied & $\begin{array}{c}\text { Eventually } \\
\text { Treated }\end{array}$ \\
\hline 1 & 2004 & 45 & 34 & 5 & 1 \\
2 & 2006 & 36 & 27 & 10 & 6 \\
3 & 2008 & 41 & 20 & 4 & 3 \\
4 & 2010 & 28 & 19 & 5 & 4 \\
5 & 2012 & 37 & 51 & 13 & 10 \\
6 & 2014 & 31 & 40 & 24 & 16 \\
7 & 2015 & 28 & 26 & 12 & 11 \\
8 & 2016 & 27 & 22 & 10 & 9 \\
\hline & Total & 273 & 239 & 83 & 60 \\
\hline
\end{tabular}

Notes: The Reapplied column indicates those who were from a previous cohort and reapplied to participate in the workshop. The Eventually Treated column are those who reapplied and were eventually treated. One person in cohort 3 died and was removed from the sample. Seven people could not be located and were assumed to have nonacademic jobs. 
Table 2: Balance Between Treatment and Control Groups Based on Initial Assignment

\begin{tabular}{lrrr} 
& Treated & Control & p-value \\
\hline Top 10 PhD Institution & 0.319 & 0.297 & 0.598 \\
Top 20 (11-20) PhD Institution & 0.245 & 0.238 & 0.856 \\
Top 40 (21-40) PhD Institution & 0.187 & 0.205 & 0.605 \\
PhD non-US & 0.081 & 0.100 & 0.435 \\
Academic First Job & 0.890 & 0.858 & 0.270 \\
First Job Top 10 Rank & 0.121 & 0.105 & 0.563 \\
First Job Top 11-20 Rank & 0.088 & 0.071 & 0.486 \\
First Job Top 21-40 Rank & 0.092 & 0.067 & 0.307 \\
First Job Top 41-100 Rank & 0.165 & 0.138 & 0.402 \\
First Job 201+ Rank & 0.333 & 0.427 & 0.030 \\
Pre-Treatment Coauthors & 1.293 & 1.552 & 0.280 \\
PhD Year & 2007.1 & 2008.1 & 0.008 \\
\hline
\end{tabular}


Table 3: IV Estimates of Intention to Treat Effects on Publication Outcomes

\begin{tabular}{|c|c|c|c|c|c|c|c|}
\hline VARIABLES & $\begin{array}{c}\text { Total } \\
\text { Publications } \\
\end{array}$ & $\begin{array}{c}\text { Top Tier } \\
\text { Publications }\end{array}$ & $\begin{array}{c}\text { Top Field } \\
\text { Publications }\end{array}$ & $\begin{array}{c}\text { Other } \\
\text { Refereed } \\
\text { Publications }\end{array}$ & Coauthors & $\begin{array}{c}\text { Coauthors } \\
x \\
\text { CeMENT } \\
\end{array}$ & $\begin{array}{c}\text { Pre-tenure } \\
\text { Citations }\end{array}$ \\
\hline \multicolumn{8}{|l|}{ Full Sample } \\
\hline CeMENT Treatment & $\begin{array}{c}1.550 * * * \\
{[0.459]}\end{array}$ & $\begin{array}{c}0.213 * * \\
{[0.084]}\end{array}$ & $\begin{array}{c}0.376 \\
{[0.236]}\end{array}$ & $\begin{array}{c}0.961 * * \\
{[0.398]}\end{array}$ & $\begin{array}{c}3.025 * * * \\
{[0.942]}\end{array}$ & $\begin{array}{c}2.995 * * * \\
{[0.940]}\end{array}$ & $\begin{array}{c}43.356 * * \\
{[17.326]}\end{array}$ \\
\hline \multicolumn{8}{|l|}{ Pretreatment } \\
\hline Coauthors & $\begin{array}{c}0.789 * * * \\
{[0.067]}\end{array}$ & $\begin{array}{c}-0.002 \\
{[0.012]}\end{array}$ & $\begin{array}{c}0.140 * * * \\
{[0.035]}\end{array}$ & $\begin{array}{c}0.651^{* * *} \\
{[0.058]}\end{array}$ & $\begin{array}{c}0.721^{* * *} \\
{[0.138]}\end{array}$ & $\begin{array}{c}0.717 * * * \\
{[0.138]}\end{array}$ & $\begin{array}{c}16.810 * * * \\
{[2.541]}\end{array}$ \\
\hline R-squared & 0.393 & 0.052 & 0.160 & 0.315 & 0.126 & 0.126 & 0.251 \\
\hline Mean & 6.174 & 0.266 & 1.998 & 3.910 & 5.914 & 5.885 & 96.99 \\
\hline \multicolumn{8}{|l|}{ Ranked Academic } \\
\hline CeMENT Treatment & $\begin{array}{l}1.326 * * \\
{[0.655]}\end{array}$ & $\begin{array}{c}0.210 \\
{[0.134]}\end{array}$ & $\begin{array}{c}0.231 \\
{[0.326]}\end{array}$ & $\begin{array}{c}0.885 \\
{[0.577]}\end{array}$ & $\begin{array}{c}3.433 * * \\
{[1.516]}\end{array}$ & $\begin{array}{c}3.413 * * \\
{[1.515]}\end{array}$ & $\begin{array}{c}16.317 \\
{[25.722]}\end{array}$ \\
\hline \multicolumn{8}{|l|}{ Pretreatment } \\
\hline Coauthors & $\begin{array}{c}0.787 * * * \\
{[0.086]}\end{array}$ & $\begin{array}{c}-0.009 \\
{[0.017]}\end{array}$ & $\begin{array}{c}0.126^{* * *} \\
{[0.043]}\end{array}$ & $\begin{array}{c}0.671 * * * \\
{[0.075]}\end{array}$ & $\begin{array}{c}0.699 * * * \\
{[0.198]}\end{array}$ & $\begin{array}{c}0.696 * * * \\
{[0.198]}\end{array}$ & $\begin{array}{c}16.455^{* * *} \\
{[3.359]}\end{array}$ \\
\hline R-squared & 0.411 & 0.068 & 0.210 & 0.327 & 0.131 & 0.131 & 0.251 \\
\hline Mean & 6.590 & 0.362 & 2.349 & 3.878 & 6.583 & 6.551 & 112.6 \\
\hline \multicolumn{8}{|c|}{ Unranked \& Non-academic } \\
\hline CeMENT Treatment & $\begin{array}{c}1.627 * * \\
{[0.637]}\end{array}$ & $\begin{array}{c}0.117 \\
{[0.078]}\end{array}$ & $\begin{array}{c}0.254 \\
{[0.325]}\end{array}$ & $\begin{array}{c}1.256^{* *} \\
{[0.543]}\end{array}$ & $\begin{array}{c}2.282 * * \\
{[0.912]}\end{array}$ & $\begin{array}{c}2.229 * * \\
{[0.903]}\end{array}$ & $\begin{array}{c}61.317^{* * *} \\
{[21.693]}\end{array}$ \\
\hline \multicolumn{8}{|l|}{ Pretreatment } \\
\hline Coauthors & $\begin{array}{c}0.817 * * * \\
{[0.116]}\end{array}$ & $\begin{array}{l}0.025 * \\
{[0.014]}\end{array}$ & $\begin{array}{c}0.184^{* * *} \\
{[0.059]}\end{array}$ & $\begin{array}{c}0.607 * * * \\
{[0.099]}\end{array}$ & $\begin{array}{c}0.742 * * * \\
{[0.166]}\end{array}$ & $\begin{array}{c}0.738 * * * \\
{[0.164]}\end{array}$ & $\begin{array}{c}19.988 * * * \\
{[3.942]}\end{array}$ \\
\hline R-squared & 0.418 & 0.112 & 0.184 & 0.367 & 0.210 & 0.210 & 0.343 \\
\hline Mean & 5.525 & 0.115 & 1.450 & 3.960 & 4.870 & 4.845 & 72.69 \\
\hline \multicolumn{8}{|l|}{ Full Sample } \\
\hline CeMENT Treatment & $\begin{array}{c}0.572 * \\
{[0.346]}\end{array}$ & $\begin{array}{c}0.217 * * * \\
{[0.084]}\end{array}$ & $\begin{array}{c}0.284 \\
{[0.236]}\end{array}$ & $\begin{array}{c}0.071 \\
{[0.289]}\end{array}$ & & & $\begin{array}{c}30.955^{*} \\
{[17.021]}\end{array}$ \\
\hline \multicolumn{8}{|l|}{ Pretreatment } \\
\hline Coauthors & $\begin{array}{c}0.556 * * * \\
{[0.052]}\end{array}$ & $\begin{array}{c}-0.001 \\
{[0.013]}\end{array}$ & $\begin{array}{c}0.118 * * * \\
{[0.035]}\end{array}$ & $\begin{array}{c}0.439 * * * \\
{[0.043]}\end{array}$ & & & $\begin{array}{c}13.856 * * * \\
{[2.541]}\end{array}$ \\
\hline \multicolumn{8}{|l|}{ Add Pre-tenure } \\
\hline Coauthors & $\begin{array}{c}0.323 * * * \\
{[0.016]}\end{array}$ & $\begin{array}{l}-0.001 \\
{[0.004]}\end{array}$ & $\begin{array}{c}0.030 * * * \\
{[0.011]}\end{array}$ & $\begin{array}{c}0.294 * * * \\
{[0.014]}\end{array}$ & & & $\begin{array}{c}4.099 * * * \\
{[0.796]}\end{array}$ \\
\hline R-squared & 0.660 & 0.052 & 0.173 & 0.644 & & & 0.289 \\
\hline Mean & 6.174 & 0.266 & 1.998 & 3.910 & & & 96.99 \\
\hline
\end{tabular}

Notes: There are 512 observations in the full sample, 312 in the ranked sample and 200 in the unranked sample. Standard errors in brackets. All regressions include dummy variables for each cohort and for years 4 to $16+$ since PhD. F-statistic for the first stage regressors is 40.34 for the full sample, 23.13 for the ranked sample, and 17.6 for the unranked sample. ${ }^{*} \mathrm{p}<.10, * * \mathrm{p}<.05$, $* * * \mathrm{p}<.01$. 


\section{Appendix 1: Web of Science Search Process}

The collection of publication data was time consuming. We started by collecting information on publications and CVs for individuals in our sample. Based on this information, we created a list of search queries for everyone in the CeMENT data. Each search query includes names, publication year intervals and affiliations. For names, we use both full names and name initials, because publications indexed in WOS prior to 2008 included only last names and initials for first and middle name. We limit the publication year intervals to be from 5 years prior to $\mathrm{PhD}$ year to 2018. The affiliations are the job institutions or affiliations of each person. Such information could be found on the job information collected in in the CVs. Institution names must be changed according to the Web of Science organization enhanced index.

For example, supposed that we have a person in the data named Katherine R. McDonald, who graduated in the 2008 from University of Kansas, and she worked in the University of Chicago from 2009 to 2013 and switched to Federal Reserve Bank of Boston after 2013. ${ }^{3}$ Then the search query for her would be:

$$
\begin{aligned}
& (\mathrm{AU}=\text { "McDonald, Katherine” or AU = McDonald, KR or AU = “McDonald, K”) and } \\
& (\mathrm{PY}=(2003-2018)) \text { and }(\mathrm{OG}=\text { "University of Kansas” or OG = "University of Chicago" } \\
& \text { or OG = "Federal Reserve Bank - Boston") }
\end{aligned}
$$

The search with the name "McDonald, KR" would results in all the records with the full name “McDonald, Katherine R.” For people without a middle name (or middle name is not found), the search using last name and first name initials would result in records with same last name but not same first name. For example, paper published by McDonald, Kathy or McDonald,

\footnotetext{
${ }^{3}$ This is not a real person.
} 
Kevin are likely to be found. Economics papers published before 2006 and health economics papers published in health journals are more likely to be published using name initials. We automated this search process by creating Python code to scrape search results from WOS.

After searching and downloading the result files from WOS for each person, we put the data together and hand-validated publications using information from the CVs. We use author's full names, field, institutions and journals to find the false records.

There are several potential limitations to our data. First, the data collection is based on online searches. We were not able to find all the information for everyone in the data, making it less consistent. Second, because of the query limitations in WOS, we cannot simply use the WOS search results only. The search queries vary by each person. Some searches returned zero records and required updating. The screening process may have introduced coding errors. Most of the CV searches were done in 2017, however publications were found in WOS through the third quarter of 2018. 


\section{Appendix 2}

Table A1: IV Estimates of Intention to Treat Effects on Publication Outcomes

\begin{tabular}{|c|c|c|c|c|c|c|c|}
\hline VARIABLES & $\begin{array}{c}\text { Total } \\
\text { Publications } \\
\end{array}$ & $\begin{array}{c}\text { Top Tier } \\
\text { Publications }\end{array}$ & $\begin{array}{c}\text { Top Field } \\
\text { Publications }\end{array}$ & $\begin{array}{c}\text { Other } \\
\text { Refereed } \\
\text { Publications }\end{array}$ & Coauthors & $\begin{array}{c}\text { Coauthors } \\
\mathbf{x} \\
\text { CeMENT } \\
\end{array}$ & $\begin{array}{c}\text { Pre-tenure } \\
\text { Citations } \\
\end{array}$ \\
\hline \multicolumn{8}{|l|}{ Full Sample } \\
\hline$\overline{\text { CeMENT Treatment }}$ & $\begin{array}{c}1.911^{* * *} \\
{[0.557]}\end{array}$ & $\begin{array}{c}0.214^{* *} \\
{[0.102]}\end{array}$ & $\begin{array}{c}0.506 * \\
{[0.282]}\end{array}$ & $\begin{array}{c}1.190 * * \\
{[0.482]}\end{array}$ & $\begin{array}{c}3.458^{* * *} \\
{[1.160]}\end{array}$ & $\begin{array}{c}3.412^{* * *} \\
{[1.158]}\end{array}$ & $\begin{array}{c}49.832 * * \\
{[21.791]}\end{array}$ \\
\hline \multicolumn{8}{|l|}{ Pretreatment } \\
\hline Coauthors & $\begin{array}{c}0.825 * * * \\
{[0.088]}\end{array}$ & $\begin{array}{c}-0.003 \\
{[0.016]}\end{array}$ & $\begin{array}{c}0.120 * * * \\
{[0.044]}\end{array}$ & $\begin{array}{c}0.708^{* * *} \\
{[0.076]}\end{array}$ & $\begin{array}{c}0.787 * * * \\
{[0.182]}\end{array}$ & $\begin{array}{c}0.784^{* * *} \\
{[0.182]}\end{array}$ & $\begin{array}{c}18.231^{* * *} \\
{[3.423]}\end{array}$ \\
\hline R-squared & 0.273 & 0.042 & 0.085 & 0.244 & 0.088 & 0.087 & 0.196 \\
\hline Mean & 7.348 & 0.321 & 2.356 & 4.671 & 6.940 & 6.907 & 124.4 \\
\hline \multicolumn{8}{|l|}{ Ranked Academic } \\
\hline$\overline{\text { CeMENT Treatment }}$ & $\begin{array}{l}1.882 * * \\
{[0.754]}\end{array}$ & $\begin{array}{c}0.221 \\
{[0.153]}\end{array}$ & $\begin{array}{c}0.442 \\
{[0.372]}\end{array}$ & $\begin{array}{l}1.220^{*} \\
{[0.661]}\end{array}$ & $\begin{array}{c}4.217^{* *} \\
{[1.750]}\end{array}$ & $\begin{array}{c}4.162 * * \\
{[1.750]}\end{array}$ & $\begin{array}{c}25.352 \\
{[30.471]}\end{array}$ \\
\hline \multicolumn{8}{|l|}{ Pretreatment } \\
\hline Coauthors & $\begin{array}{c}0.819 * * * \\
{[0.106]}\end{array}$ & $\begin{array}{c}-0.005 \\
{[0.022]}\end{array}$ & $\begin{array}{c}0.127^{* *} \\
{[0.052]}\end{array}$ & $\begin{array}{c}0.697 * * * \\
{[0.093]}\end{array}$ & $\begin{array}{c}0.743^{* * *} \\
{[0.246]}\end{array}$ & $\begin{array}{c}0.742^{* * *} \\
{[0.246]}\end{array}$ & $\begin{array}{c}17.316^{* * *} \\
{[4.285]}\end{array}$ \\
\hline R-squared & 0.286 & 0.053 & 0.105 & 0.266 & 0.100 & 0.099 & 0.183 \\
\hline Mean & 7.797 & 0.429 & 2.753 & 4.615 & 7.688 & 7.654 & 142.4 \\
\hline \multicolumn{8}{|c|}{ Unranked \& Non-academic } \\
\hline CeMENT Treatment & $\begin{array}{l}1.741^{* *} \\
{[0.822]}\end{array}$ & $\begin{array}{c}0.093 \\
{[0.101]}\end{array}$ & $\begin{array}{c}0.204 \\
{[0.410]}\end{array}$ & $\begin{array}{c}1.444 * * \\
{[0.692]}\end{array}$ & $\begin{array}{c}2.158^{*} \\
{[1.179]}\end{array}$ & $\begin{array}{c}2.112 * \\
{[1.168]}\end{array}$ & $\begin{array}{c}65.718 * * \\
{[29.386]}\end{array}$ \\
\hline \multicolumn{8}{|l|}{ Pretreatment } \\
\hline Coauthors & $\begin{array}{c}0.865^{* * *} \\
{[0.162]}\end{array}$ & $\begin{array}{c}0.014 \\
{[0.020]}\end{array}$ & $\begin{array}{c}0.121 \\
{[0.081]}\end{array}$ & $\begin{array}{c}0.730 * * * \\
{[0.136]}\end{array}$ & $\begin{array}{c}0.791^{* * *} \\
{[0.232]}\end{array}$ & $\begin{array}{c}0.786 * * * \\
{[0.230]}\end{array}$ & $\begin{array}{c}22.215^{* * *} \\
{[5.793]}\end{array}$ \\
\hline R-squared & 0.318 & 0.119 & 0.153 & 0.293 & 0.154 & 0.153 & 0.315 \\
\hline Mean & 6.575 & 0.134 & 1.672 & 4.769 & 5.649 & 5.619 & 93.42 \\
\hline \multicolumn{8}{|l|}{ Full Sample } \\
\hline CeMENT Treatment & $\begin{array}{c}0.796 * \\
{[0.416]}\end{array}$ & $\begin{array}{c}0.218^{* *} \\
{[0.103]}\end{array}$ & $\begin{array}{c}0.396 \\
{[0.281]}\end{array}$ & $\begin{array}{c}0.183 \\
{[0.347]}\end{array}$ & & & $\begin{array}{c}35.151^{*} \\
{[21.333]}\end{array}$ \\
\hline \multicolumn{8}{|l|}{ Pretreatment } \\
\hline Coauthors & $\begin{array}{c}0.572^{* * *} \\
{[0.067]}\end{array}$ & $\begin{array}{c}-0.002 \\
{[0.016]}\end{array}$ & $\begin{array}{c}0.095 * * \\
{[0.045]}\end{array}$ & $\begin{array}{c}0.479 * * * \\
{[0.055]}\end{array}$ & & & $\begin{array}{c}14.890 * * * \\
{[3.416]}\end{array}$ \\
\hline \multicolumn{8}{|l|}{ Add Pre-tenure } \\
\hline Coauthors & $\begin{array}{c}0.322 * * * \\
{[0.019]}\end{array}$ & $\begin{array}{c}-0.001 \\
{[0.005]}\end{array}$ & $\begin{array}{l}0.032 * * \\
{[0.013]}\end{array}$ & $\begin{array}{c}0.291 * * * \\
{[0.016]}\end{array}$ & & & $\begin{array}{c}4.245^{* * *} \\
{[0.962]}\end{array}$ \\
\hline R-squared & 0.599 & 0.042 & 0.102 & 0.613 & & & 0.238 \\
\hline Mean & 7.348 & 0.321 & 2.356 & 4.671 & & & 124.4 \\
\hline
\end{tabular}

Notes: There are 365 observations in the full sample, 231 in the ranked sample and 134 in the unranked sample. Standard errors in brackets. All regressions include dummy variables for each cohort and for years 4 to 16+ since $\mathrm{PhD}$. F-statistic for the first stage regressors is 63.65 for the full sample, 43.89 for the ranked sample, and 18.61 for the unranked sample. ${ }^{*} \mathrm{p}<.10,{ }^{* *} \mathrm{p}<.05,{ }^{* * *} \mathrm{p}<.01$. 